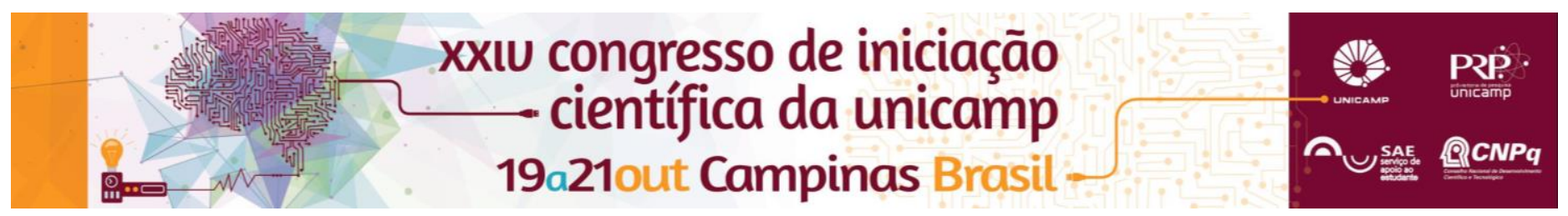

\title{
Separação Cega de Fontes e Análise de Componentes Independentes.
}

\author{
Marcelo Ramos Romano*, Romis Attux.
}

\section{Resumo}

O propósito desse trabalho foi realizar um estudo sobre o tópico de Análise de Componentes Independentes (ICA) no contexto de Separação Cega de Fontes (BSS). Nele, foram estudados alguns dos principais algoritmos de ICA, como os baseados na maximização da não-gaussianidade e na minimização da informação mútua. O estudo foi embasado por uma análise comparativa feita a partir de simulações.

\section{Palavras-chave:}

separação cega de fontes, análise de componentes independentes, processamento de sinais.

\section{Introdução}

BSS consiste na separação de sinais aleatórios que são observados, por meio de sensores, exclusivamente na forma de misturas. ICA é um método de BSS que requer o pressuposto de que os sinais que misturados sejam independentes entre si. Além disso, assume-se que a mistura dos sinais seja linear e instantânea no tempo. Portanto, o vetor de misturas será uma transformação linear do vetor de fontes, sendo que desconhecemos tanto as amostras do vetor de fontes como a matriz de mistura. Almeja-se obter a transformação inversa à matriz de mistura, de modo a se recuperar 0 vetor de fontes desejado. Uma das formas de se obter a matriz inversa é notar que, ao se multiplicar o vetor de misturas por uma possível candidata a matriz de separação, será obtida, em cada entrada do possível vetor solução, uma combinação linear das próprias entradas do vetor de fontes. $O$ que queremos é que apenas um dos coeficientes dessa combinação seja não nulo. Para que isso ocorra, pode-se invocar o Teorema do Limite Central $^{1}$, do qual decorre que a soma de variáveis aleatórias independentes possui a distribuição "mais gaussiana" que as das próprias variáveis aleatórias que estão sendo somadas. Portanto, ao se maximizar a nãogaussianidade do vetor solução, estar-se-á forçando que apenas um coeficiente da combinação linear citada seja não nulo.

Com isso, torna-se possível utilizar funções que são medidas de gaussianidade de um sinal aleatório para realizar ICA, e os algoritmos desenvolvidos envolveram medidas desse tipo, como a curtose e a negentropia. Além disso, também foi utilizado um algoritmo imuno-inspirado que buscou recuperar a independência das fontes, usando quantificação direta via informação mútua. Foi ainda empregado o conceito de máxima verossimilhança, na sua forma de maximização do fluxo de informação (infomax) ${ }^{1}$.

\section{Resultados e Discussão}

Para a simulação dos algoritmos de maximização da curtose, da negentropia, do fluxo de informação (infomax) e de minimização da informação mútua, utilizou-se o software MATLAB. Com isso, geramos sinais aleatórios sintéticos tanto supergaussianos como subgaussianos. Também determinamos qual seria a matriz de mistura, obtendo as amostras do vetor de mistura através da multiplicação do vetor de fontes por essa matriz.

Nos testes, foi avaliada tanto a convergência para sinais supergaussianos como para subgaussianos. Além disso, testaram-se vários passos diferentes, já que os algoritmos utilizados foram baseados no gradiente das funções custo. Ademais, testaram-se tanto cenários com duas fontes independentes como com três fontes.

Pode-se perceber que o algoritmo baseado na curtose foi o que obteve o melhor desempenho, como ilustra a figura 1 abaixo (devido a questões de espaço, só foi possível apresentar um cenário). Nessa figura, o eixo horizontal mede o número de iterações do algoritmo e o eixo vertical o erro quadrático médio entre o sinal recuperado e a respectiva fonte. As curvas em azul, verde e vermelho representam, respectivamente, a evolução dos algoritmos baseados na curtose, no princípio infomax e na negentropia.

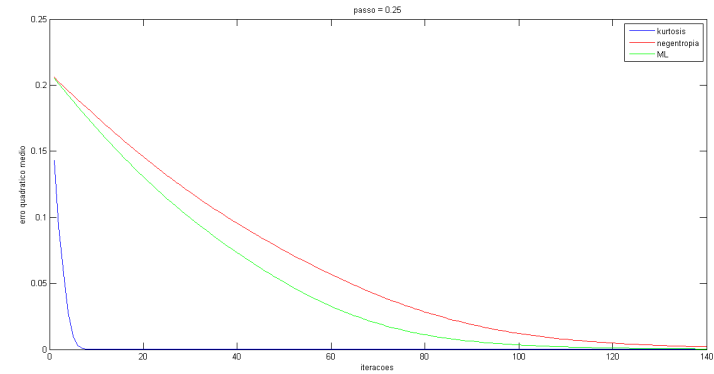

Figura 1. Gráfico que ilustra a convergência dos diferentes algoritmos.

\section{Conclusões}

Consideramos que o estudo dos algoritmos de ICA tenha sido proveitoso, e que os resultados das simulações tenham sido satisfatórios. A iniciação foi de grande importância formativa para o bolsista.

\section{Agradecimentos}

Agradecemos ao CNPq o apoio financeiro.

${ }^{1}$ Hyvärinen, A.; Karhunen, J.; Oja, E.. Independent Component Analysis. Wiley, 2001 